\title{
Factors affecting the solution of a parental dilemma in albatrosses: at what age should chicks be left unattended?
}

\author{
PAULO CATRY* $†$, RICHARD A. PHILLIPS*, JAUME FORCADA* \& JOHN P. CROXALL* \\ *British Antarctic Survey, Natural Environment Research Council \\ $\dagger$ †nidade de Investigação em Eco-Etologia, Instituto Superior de Psicologia Aplicada \\ (Received 24 February 2005; initial acceptance 7 June 2005; \\ final acceptance 20 October 2005; published online 11 July 2006; MS. number: 8479)
}

\begin{abstract}
With rare exceptions, avian offspring are continuously attended by one parent for at least the first few days after hatching. The duration of this phase of the nesting cycle is regulated by a trade-off between the benefits of brooding/guarding and those of foraging. We manipulated offspring age in grey-headed albatrosses, Thalassarche chrysostoma, by swapping chicks between nests. Parents given chicks 6 days older than their own shortened brooding by only 1.2 days, and parents given chicks 6 days younger than their own extended brooding by 1.4 days. Despite being relatively unresponsive to chick age, parents adjusted brooding in relation to calendar date and to chick condition. The results suggest that adults do not use chick age per se as a cue, but instead probably use an internal timer, and fine-tune the decision to end brooding according to date and chick mass. The duration of brood guarding did not correlate with adult body condition, suggesting that adults had a sufficient safety margin to allow them to respond to chick needs without compromising their own residual reproductive value. Chick survival at the end of brood guarding was strongly dependent on calendar date (early and late chicks suffered higher mortality), which suggests that greyheaded albatrosses benefit from breeding synchronously. We conclude that the length of the brood-guarding period is dependent on chick condition and seasonal variation in chick predation risk.
\end{abstract}

(c) 2006 The Association for the Study of Animal Behaviour. Published by Elsevier Ltd. All rights reserved.

With few exceptions, avian offspring hatch largely unable to maintain internal body temperature without parental assistance (Visser 1998). Hence, in the first days or weeks of chick life, parental brooding occurs in virtually all avian taxa (Düttman et al. 1998). As chicks grow, their thermoregulatory abilities gradually improve until homeothermy can be achieved without brooding, albeit at comparatively high energetic cost (Visser 1998). Parental brooding can be extended beyond the onset of independent homeothermy in chicks as an energy-saving mechanism (Ricklefs \& Roby 1983; Weathers et al. 2000). In some species, parents continue to guard offspring (by standing or sitting at the side of the nest) even when chicks have developed sufficiently to gain little apparent energetic benefit from brooding. This behaviour can confer protection against predators, or allow the prompt resumption of brooding

Correspondence and present address: P. Catry, Unidade de Investigação em Eco-Etologia, Instituto Superior de Psicologia Aplicada, Rua Jardim do Tabaco 44, 1100 Lisboa, Portugal (email: paulo.catry@netc.pt). R. Phillips, J. Forcada and J. P. Croxall are at the British Antarctic Survey, Natural Environment Research Council, High Cross, Madingley Road, Cambridge CB3 OET, U.K. if environmental conditions deteriorate abruptly, for example during poor weather (Weathers et al. 2000).

In altricial species with biparental care, continual attendance at the nest by one parent means that only one member of the pair can forage at a time. Regulation of the duration of brooding/guarding is generally seen as the balance between opposing selection pressures. As chicks age, they improve both thermoregulatory capacity and the ability to resist predation, which in itself should induce parents to extend brooding for as long as possible. However, as chicks grow, they also demand more food, which requires a switch from one parent guarding to both foraging simultaneously, heralding the end of the broodguarding period. Adequate body reserves are essential for adults to sustain fasting while guarding the chick, and adult body mass frequently deteriorates during this phase as a result of constraints on the time spent foraging (Weimerskirch \& Lys 2000; Shaffer et al. 2003), stimulating parents to cease brooding before their body reserves fall to dangerously low levels. These trade-offs should lead to an optimal solution concerning the duration of brooding. However, this is likely to be modulated by stochastic (e.g. weather, foraging success) and deterministic factors (e.g. parental age, foraging ability), leading to 
variation in parental body reserves, as well as in chick nutritional status (which affects thermoregulation and antipredator behaviour). Another modulating factor, not considered in previous studies, is predation pressure, which can vary seasonally, for example if synchronized breeding results in predator swamping (Ims 1990). Somewhat surprisingly, trade-offs between foraging and brooding have been investigated only rarely in altricial birds, and little is known of the relative importance of these factors in regulating the decision to end brooding (but see Tveraa et al. 1998; Brodin et al. 2003; Varpe et al. 2004).

In pelagic seabirds, the dilemma of leaving or staying is particularly acute given that foraging trips can last up to several days, and an unattended, young and hence vulnerable chick is potentially exposed for long periods between visits. The duration of brood guarding in albatrosses and petrels (Procellariiformes) is highly variable, even within the same climatic region, for example lasting just 2-3 days in Antarctic prions, Pachyptila desolata (Ricklefs \& Roby 1983), but 3-6 weeks in albatrosses (Tickell 2000). Part of the variation can be accounted for by nest site characteristics; brood-guarding is shorter in burrow- than surface-nesters (Warham 1990). However, there are large variations even within these two general groups (e.g. Ricklefs \& Roby 1983; Hunter 1984). For example, the differences between the two giant petrels, Macronectes halli and M. giganteus, breeding at South Georgia are remarkable, in spite of their striking morphological similarities and the shared nesting environment. Although the duration of brooding itself is virtually the same for each species (means of 19.7 and 18.4 days, respectively), the subsequent guarding period is five times longer in $M$. halli (12.5 days) than M. giganteus (2.4 days; Hunter 1984). Intraspecific variation in brood-guarding duration provides a good opportunity for studying the selection pressures acting on this behaviour.

We investigated the relative importance of flexibility and constraint in the regulation of brood guarding in grey-headed albatrosses, Thalassarche chrysostoma. Albatrosses, in common with other extremely long-lived seabirds, generally behave as 'prudent parents' (Drent \& Daan 1980), and should avoid voluntarily exposing themselves to large mortality risks for the sake of a single offspring or breeding attempt (Sæther et al. 1993; Weimerskirch 1999; Weimerskirch et al. 2001). As such, parental decisions during brood guarding should not impact on subsequent adult survival, but ought to reflect the observed patterns of chick mortality at the transition from guarding to nonguarding, modulated by environmental variability and unpredictability.

We manipulated chick age (by switching chicks between nests) to assess whether parents respond to age-related development of chick characteristics and behaviour when choosing between leaving and staying. If parent albatrosses have a wide safety margin in body reserves, we would expect them to respond to such manipulations by making an almost complete adjustment in the duration of brooding, leaving the foster chicks at approximately the same age as appropriate controls. If, however, parents are strongly constrained in their decisions, we would expect them to be unable to lengthen the brooding period when given a younger chick, leaving the duration of the brooding period almost unchanged in spite of the manipulations. In this second scenario, we would also predict parental condition to be a strong predictor of the duration of brood guarding in unmanipulated pairs, whereas chick condition or the timing of breeding should be relatively unimportant.

\section{METHODS}

\section{Monitoring Attendance and Survival}

Fieldwork was carried out at Bird Island, South Georgia, which during the last complete census (1989-1991) held a total breeding population of 11580 grey-headed albatross pairs, with 80900 pairs in the archipelago as a whole (Prince et al. 1994). We studied two adjacent colonies (colony B and colony E, $500 \mathrm{~m}$ apart, with the same general characteristics and aspect) in the 2002-2003 breeding season. All nests in each colony were marked with numbered tags, and laying dates (colony E only) and hatching dates (colonies $\mathrm{B}$ and $\mathrm{E}$ ) determined from daily visits. Albatrosses lay a single-egg clutch. Once the chick hatched, we monitored attendance of the adults at the nest and chick survival three times a day (at 0930, 1530 and 2130 hours) in colony B, and daily (1100 hours) in colony E, until 1 week after the last chick was left unattended. Chick survival was then monitored daily for another month, and weekly thereafter until fledging. No attempt was made to distinguish between brooding and guarding without brooding (the latter was in any case rare). During brood guarding most foraging trips in our study colonies lasted 2-4 days (range $1-7$ ).

The study was carried out with permission of the Government of South Georgia and the South Sandwich Islands.

\section{Experimental Manipulation}

To assess the influence of chick age on the decision to terminate brood guarding, we created two experimental groups and respective controls in colony $\mathrm{B}$. The first experimental group ('Small Chick' pairs) was formed by pairs whose chick was removed when 12 days old and replaced by a randomly selected chick aged 6 days old. Each of these pairs had a control, whose original chick hatched on the same date (or a date as close as possible in the available pool) as the one from the experimental pair, and which received a 12-day-old chick in exchange for its own, also 12 days after hatching. Pairs in the second experimental group ('Large Chick' pairs) received a 12day-old chick in exchange for their own 6-day-old chick. Controls were created in an analogous way to those for the Small Chick experimental group. All chicks were immediately adopted, preened and brooded, as typically happens with petrels with young chicks. Albatross parents know their own nest but not their own chick, and previous experimental chick swapping did not result in any desertions or movements to feed the original chick (Phillips $\&$ Croxall 2003). There is therefore no reason to expect 
that the experimental manipulation should have any effect on the likelihood of failure early in brooding. Only six $(3.1 \%)$ of 195 experimental chicks died before 11 days of age, which compares with four (3.9\%) of 103 unmanipulated chicks. Excluding six failures that occurred early in the brooding period (chick $<11$ days old), there were 49 Small Chick and 46 Large Chick pairs, with, respectively, 49 and 45 controls for each group.

The experimental manipulation resulted in some Small Chicks being left alone at a comparatively young age. To avoid any unnecessary mortality from cold exposure or predation, we fostered any chicks left when younger than 22 days to grey-headed albatross pairs that were still incubating addled eggs. These chicks were successfully adopted in every case.

\section{Adult and Chick Body Condition}

During brood guarding, adult albatrosses in colony B were captured by hand en route to the sea just after being relieved by their partner at the nest. These birds were measured (bill length, bill depth, wing length), weighed and then released. No adults were injured and none deserted as a result of our measurements.

Chicks involved in experimental manipulations were weighed on the day they were exchanged. All chicks (experimental and control) were weighed on day 21 (i.e. 21 days after hatching of the original chick in that nest). We did not attempt to weigh older chicks because of the risk of regurgitation (a defensive behaviour) and potential soiling of plumage. A few chicks could not be weighed at 21 days because of high winds, creating some slight variation in sample sizes.

\section{Definitions and Data Analysis}

We considered brood guarding to have ended on the first occasion we observed the chick alone at the nest. Throughout this paper, the variable 'date' is the number of days elapsed since 30 November (i.e. 1 December = day 1 , 2 December $=$ day 2 , etc.). There were no significant differences in mean hatching date, brood-guarding duration, chick mass at 21 days or chick survival between colonies $\mathrm{B}$ and E. Therefore, all unmanipulated pairs in colonies $\mathrm{B}$ and $\mathrm{E}$ (including controls) were pooled in analyses of broad patterns of chick survival and duration of the brood-guarding period in relation to other variables. Based on the overall distribution of values (Fig. 1), brood-guarding durations of less than 11 days $(N=3,1.5 \%$ of all measurements) were considered to be outliers (i.e. breeding failures occurring before the normal end of brooding), and eliminated from further analyses. Pairs that abandoned dead chicks were also excluded.

Preliminary plots indicated that chick survival probability showed an obvious nonlinear response to calendar date. The combined effects of date and other variables on chick survival rates were therefore examined with generalized additive models (GAM) using penalized regression splines (Wood 2003) with a binomial error structure and logit link. To assess the explanatory value of nonlinear

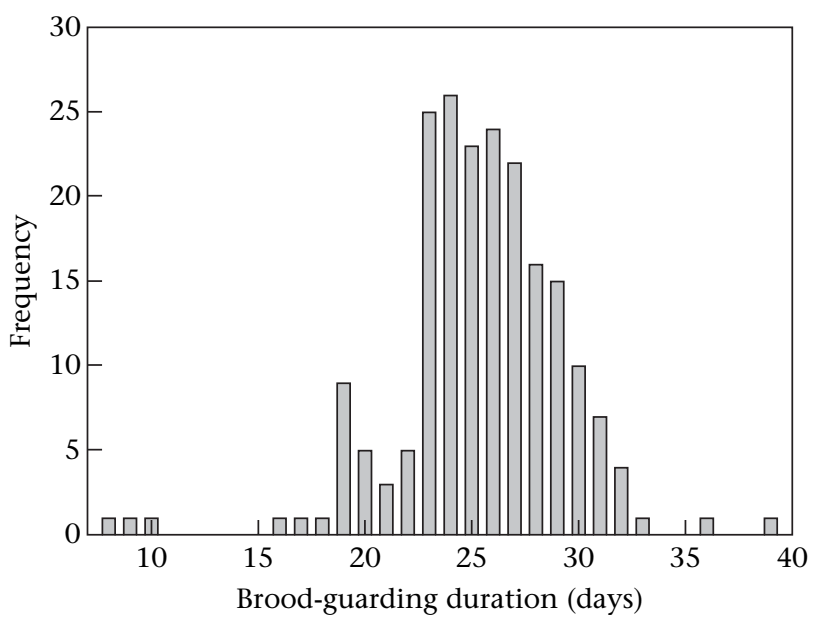

Figure 1. The duration of the brood-guarding period in a sample of 203 unmanipulated and control grey-headed albatross nests on Bird Island, South Georgia.

covariates we compared the UBRE/CGV scores calculated for each fitted model using the MGCV package for program R (Wood 2001). Other linear responses of binomial type were analysed with logistic regressions.

We incorporated adult body measurements into a principal components analysis (PCA), and used PC1 scores as a measure of body size (Rising \& Somers 1989). The unstandardized residuals of a regression of body mass on PC1 scores (regression: $r^{2}=0.44, N=122, P<0.001$ ) were used as indexes of body condition for graphical presentation, but statistical tests were carried out with uncorrected body mass as a dependent variable and PC1 scores as a covariate. To avoid possible pseudoreplication, we included only one randomly selected bird (measurement) per pair in the analyses. Growth of grey-headed albatross chicks between 6 and 21 days of age is highly variable, but on average follows a nearly linear trajectory (Huin \& Prince 2000). Hence, we calculated growth rates as the difference in mass between two measurements divided by the time (days) elapsed.

As an independent measure of adult quality, we used information on past breeding performance of our study birds (from the British Antarctic Survey database). For each bird, we calculated an index of quality as the proportion of the previous five or six (depending on data availability) breeding attempts that resulted in a fledged chick (see Cobley et al. 1998 for methodology and rationale). The quality of a pair was defined as the mean of the values of each partner. Pairs composed of individuals whose quality indexes differed by more than 0.20 were discarded from the analyses. It is conceivable that brood-guarding duration may vary seasonally because of a difference in timing of breeding by adults of different intrinsic quality, with a different body condition, or by variation in food availability. For example, individuals of higher quality or with a better body condition could both nest earlier and be able to guard their chick for longer. To examine these potentially confounding factors, we examined variation in parental body mass, egg size, chick growth and breeding success with date. Egg size in albatrosses is likely to 
indicate adult quality, given its dependence on individual effects and maternal age, and its relation with hatching success (Croxall et al. 1992). Chick growth rate indicates both parental quality and food availability (Cobley et al. 1998).

Means are presented \pm SD unless stated otherwise.

\section{RESULTS}

\section{Parental Response to Chick Age Manipulation}

Brood-guarding durations of unmanipulated greyheaded albatross chicks averaged $25.8 \pm 3.4$ days (range $16-39, N=200$; Fig. 1). The distributions of hatching dates were similar in experimental groups and their respective controls and the manipulations did not affect daily growth rate of chicks (Table 1). As a result of the 6day differences in age, at day 21 after hatching date (of the original chick in the nest), Small Chicks were $207 \mathrm{~g}$ lighter and Large Chicks were $223 \mathrm{~g}$ heavier than their respective controls (Table 1). The duration of brood guarding was 1.4 days longer for parents given Small Chicks and 1.2 days shorter for parents given Large Chicks than their respective controls (Table 1). Adjustments were therefore in the predicted direction, but were small compared to the manipulations (in both cases, switching of chicks differing in age by 6 days).

When we compared the duration of brood guarding of experimental groups and their controls with general linear models (GLMs), with hatching date and chick mass at 21 days as covariates (forced into the models, as they affected the duration of brooding in unmanipulated pairs, see below), the differences were no longer statistically significant (Small Chicks: $F_{1,93}=3.20, P=0.077$; Large Chicks: $\left.F_{1,87}=3.80, P=0.054\right)$.

Large Chicks were apparently disadvantaged by being brooded/guarded for longer than normal, as their probability of fledging (30.4\%) was lower than that of their controls (51.1\%; likelihood-ratio test: $G_{1}^{2}=4.06$, $P=0.044)$. Such a difference was, however, not evident within the first $48 \mathrm{~h}$ after the end of brooding, during which period the survival of Large Chicks $(91.3 \%$, $N=46)$ was similar to that of their controls $(88.9 \%$, $N=45$; likelihood-ratio test: $\left.G_{1}^{2}=0.15, P=0.70\right)$. The survival rate of Small Chicks (fostered to pairs with addled eggs at the end of brood guarding; see Methods) was not followed.

\section{Other Correlates of Brood Guarding}

In unmanipulated pairs, hatching date was highly and negatively correlated with brood-guarding duration (Fig. 2, Table 2). Chick mass at 21 days made a further significant, but relatively small, contribution to explaining some of the variance (Table 2). Growth of chicks was extremely variable; considering only those that survived to fledging, mass at 21 days varied from 540 to $1640 \mathrm{~g}$, that is, by a factor of three.

Adult body condition (mass corrected for size) declined as brood guarding progressed (condition $(\mathrm{g})=184.8-$ $12.97 \times$ days since hatching; $\left.F_{1,119}=10.06, P=0.002\right)$. Relative adult condition (mass scaled for size and time since hatching) had no influence on the duration of brood guarding (Table 2, model 2). Note that birds were weighed on average 10 days before the end of brood guarding, which might reduce the power of this test. However, values for condition (residuals of a multiple regression with size and days since hatching as predictors) were highly repeatable for birds weighed twice with intervals of several days between measurements (intraclass correlation coefficient: $\left.r_{i}=0.87, F_{1,13}=14.68, P<0.001\right)$.

Adult quality, as measured by past breeding performance, did not correlate with brood-guarding duration (Spearman rank correlation: $r_{\mathrm{S}}=-0.10, N=55, P=0.5$ ). Furthermore, pairs composed of one or two individuals without previous breeding experience did not brood for shorter periods than pairs in which both birds were experienced (no experience: $27.5 \pm 2.7$ days, $N=11$; with experience: $26.0 \pm 3.8$ days, $N=89$; ANOVA: $F_{1,98}=1.55$, $P=0.22)$.

\section{Potential Confounding Factors}

After accounting for body size and time since hatching (see above), no further variation in parental body mass could be explained by hatching date (GLM: $F_{1,118}=0.20$, $P=0.65)$, that is, adult condition was not measurably different for early, peak or late-nesting birds. Egg size was also

Table 1. Mean \pm SD values for selected variables and results of ANOVAs comparing the two grey-headed albatross experimental groups and their respective controls

\begin{tabular}{|c|c|c|c|c|}
\hline & Small chick $(N=49)$ & Control for small $(N=49)$ & Large chick $(N=45)$ & Control for large $(N=46)$ \\
\hline $\begin{array}{l}\text { Hatching date } \\
\text { (days from } 30 \mathrm{Nov} \text { ) }\end{array}$ & \multicolumn{2}{|c|}{$\begin{array}{c}26.6 \pm 2.1 \\
\\
\quad F_{1,96}=0.30, P=0.59\end{array}$} & \multicolumn{2}{|c|}{$F_{1,92}=0.21, P=0.65$} \\
\hline Growth rate (g/day) & \multicolumn{2}{|c|}{$F_{1,91}=0.55, P=0.46$} & \multicolumn{2}{|c|}{$F_{1,77}=0.29, P=0.87$} \\
\hline Brood guarding (days) & \multicolumn{2}{|c|}{$F_{1,94}=4.4, P=0.039$} & \multicolumn{2}{|c|}{$F_{1,88}=4.8, P=0.032$} \\
\hline Body mass on day 21 (g) & \multicolumn{2}{|c|}{$F_{1,93}=18.9, P<0.001$} & \multicolumn{2}{|c|}{$F_{1,86}=13.1, P=0.001$} \\
\hline
\end{tabular}

Degrees of freedom vary because not all chicks were weighed on all sampling occasions (see Methods). 


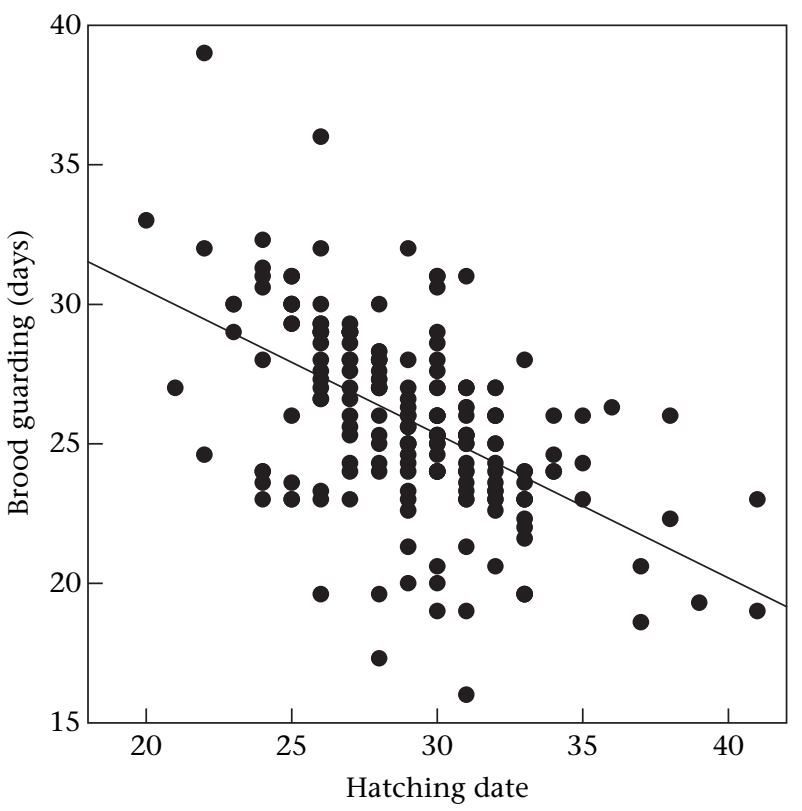

Figure 2. Variation in the duration of brood guarding in relation to date of hatching (day $1=1$ December) in grey-headed albatrosses. The line shows the least-squares linear regression. $N=200$.

not correlated with laying date $\left(F_{1,122}=0.35, R^{2}=0.03\right.$, $P=0.56)$. Chick body mass at 21 days, however, was weakly but positively correlated with hatching date $\left(F_{1,170}=4.37, R^{2}=0.025, P=0.038\right)$. The index of adult quality, based on past breeding success, did not correlate with hatching date (Spearman correlation: $r_{\mathrm{S}}=-0.10$, $N=55, P=0.5$ ). Finally, breeding success was not significantly related to laying date (logistic regression of the effect of laying date on fledging success: $G_{1}^{2}=3.13$, $N=163, \quad P=0.08, \quad \beta=-0.098 \pm 0.057 \mathrm{SE})$. There was therefore no substantive evidence that individual quality, condition or food resources differed markedly for early and late-nesting birds. A weak but significant tendency for late-hatched chicks to grow better during brooding was counteracted by a slight tendency of late-hatched chicks to suffer higher mortality rates (see below).

\section{Patterns of Chick Mortality}

There was a pronounced peak in chick mortality in the first $48 \mathrm{~h}$ after chicks were left alone for the first time. Of the 200 chicks that survived until the end of brood guarding, $12.5 \%$ died in the first $48 \mathrm{~h}$ and $38.5 \%$ died between then and fledging (at ca. 116 days after being left alone). The daily mortality rate was therefore ca. 18 times higher in the first $48 \mathrm{~h}$ than during the remainder of the nestling period (an exact value cannot be calculated as fledging date and success were recorded only on weekly visits; see Methods).

Given these survival patterns, we proceeded to identify correlates of mortality in the initial critical period and, in separate analyses, between then and fledging. We used a cutoff point of the first $48 \mathrm{~h}$ (cutoffs of the first 24 or $72 \mathrm{~h}$ in any case yielded similar results). Chick survival in the first $48 \mathrm{~h}$ unattended was modelled with the following four potential predictors: colony, calendar date on which the chick was left alone, chick age when left alone (i.e. duration of brood guarding) and chick condition (mass at 21 days old). We first fitted a GAM model with binomial error structure and logit link. Continuous predictors modelled as smoothers were date, age at partial independence and mass at 21 days; colony was modelled as a factor with two levels. Colony $(P=0.6)$ and age $(P=0.4)$ were nonsignificant and were removed from the model. The second model included only date (smoother) and mass at 21 days (linear) as highly significant $(P<0.005)$ predictors of survival. We opted to smooth the effect of date on survival by reducing the number of estimated degrees of freedom, so that results

Table 2. Factors affecting the duration of the brood-guarding phase in grey-headed albatrosses

\begin{tabular}{|c|c|c|c|c|c|c|}
\hline & Unstandardized coefficients \pm SE & Standardized $\beta$ coefficients & Sum of squares & $d f$ & $F$ & $P$ \\
\hline \multicolumn{7}{|l|}{ Model 1} \\
\hline Regression & & & 402.2 & 2 & 29.1 & $<0.001$ \\
\hline Intercept & $40.54 \pm 1.97$ & & 2912.8 & 1 & 422.0 & $<0.001$ \\
\hline Hatching date & $-0.447 \pm 0.065$ & -0.454 & 323.1 & 1 & 46.8 & $<0.001$ \\
\hline Mass at 21 days & $-0.0016 \pm 0.001$ & -0.147 & 33.9 & 1 & 4.9 & 0.028 \\
\hline Error & & & 1207.8 & 175 & & \\
\hline Total & & & 118044.0 & 178 & & \\
\hline \multicolumn{7}{|l|}{ Model 2} \\
\hline Regression & & & 172.4 & 4 & 5.58 & 0.001 \\
\hline Intercept & $40.58 \pm 6.4$ & & 303.7 & 1 & 39.3 & $<0.001$ \\
\hline Hatching date & $-0.447 \pm 0.136$ & -0.454 & 83.3 & 1 & 10.8 & 0.002 \\
\hline Mass at 21 days & $-0.0038 \pm 0.002$ & -0.147 & 33.9 & 1 & 4.4 & 0.043 \\
\hline Adult mass & $0.556 \pm 1.698$ & 0.060 & 0.9 & 1 & 0.1 & 0.741 \\
\hline Adult size & $-0.286 \pm 0.589$ & -0.087 & 1.8 & 1 & 0.2 & 0.630 \\
\hline Error & & & 285.9 & 37 & & \\
\hline Total & & & 27484.0 & 42 & & \\
\hline
\end{tabular}

The first model presents the results with the complete data set of nests for which a measure of body mass at 21 days could be obtained. The second model includes the more restricted set of nests for which parental body mass and size could be measured. Note that only one parent contributed a mass and size condition value for each nest.

Adjusted $R^{2}$ of model $1=0.24$; adjusted $R^{2}$ of model $2=0.31$. 
are less affected by short-term (daily) variations in survival. In this model, mass ( $t$ test: $t_{199}=3.045, P=0.003$ ) and date $\left(\chi_{3}^{2}=16.467, P=0.0009\right)$ were highly significant, the adjusted $R^{2}$ was 0.224 and the deviance explained was $25 \%$. Both calendar date and chick condition were important predictors of chick survival in the first $48 \mathrm{~h}$ (Fig. 3); heavier chicks had a higher survival probability and chicks left alone at the earliest dates suffered high mortality (Figs 3 and 4). Survival probability improved steeply as the season progressed, with those left around day 55, in temporal synchrony with most other chicks, the least likely to die in the first $48 \mathrm{~h}$ (Figs 3 and 4).

In contrast, survival from $48 \mathrm{~h}$ alone to fledging was not related to colony, chick condition, date or age. For the entire period from the end of brood guarding to fledging, hatching date was the only significant predictor of survival (logistic regression: $G_{1}^{2}=3.89, N=200, P=0.049$, $\beta=-0.0809 \pm 0.0418 \mathrm{SE}$ ), with chicks hatched late having a lower probability of fledging.

\section{DISCUSSION}

This study presents a number of novel conclusions concerning the regulation of brood guarding in albatrosses. First, it shows that chick mortality is high just after the end of brood guarding, and is strongly dependent on calendar date and chick condition, but is largely independent of the duration of brood guarding itself. Second, there is a marked seasonal decline in the duration of brood guarding, a pattern that, as far as we know, has not been described previously in birds. Third, and perhaps surprisingly, parents' decisions concerning the regulation of brooding seem to be largely independent not only of chick age but also of their own body condition. Below, we discuss these patterns and offer possible explanations that

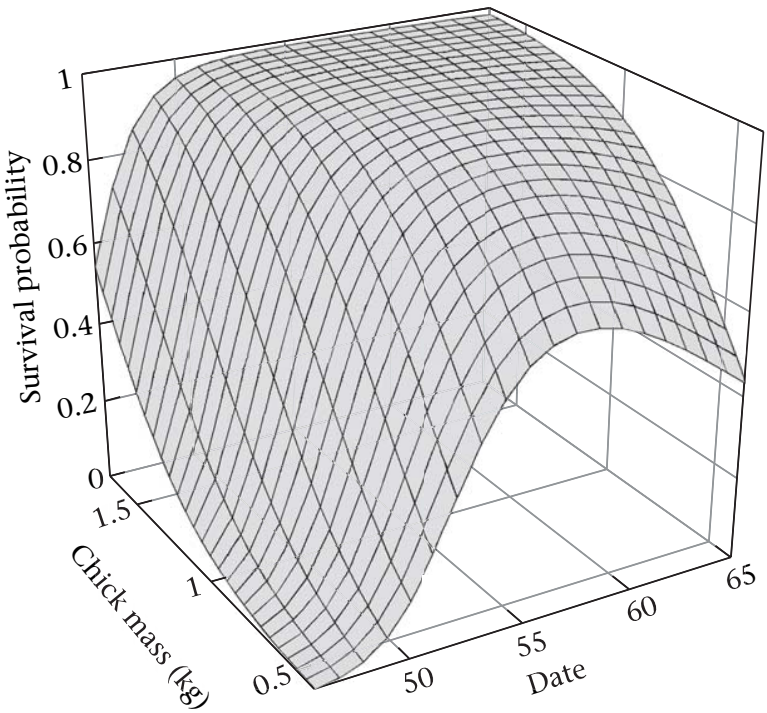

Figure 3. Surface plot depicting estimated survival probabilities of unattended grey-headed albatross chicks during the first $48 \mathrm{~h}$ alone, with chick mass at 21 days and day of parental departure (day $1=1$ December) as predictors.

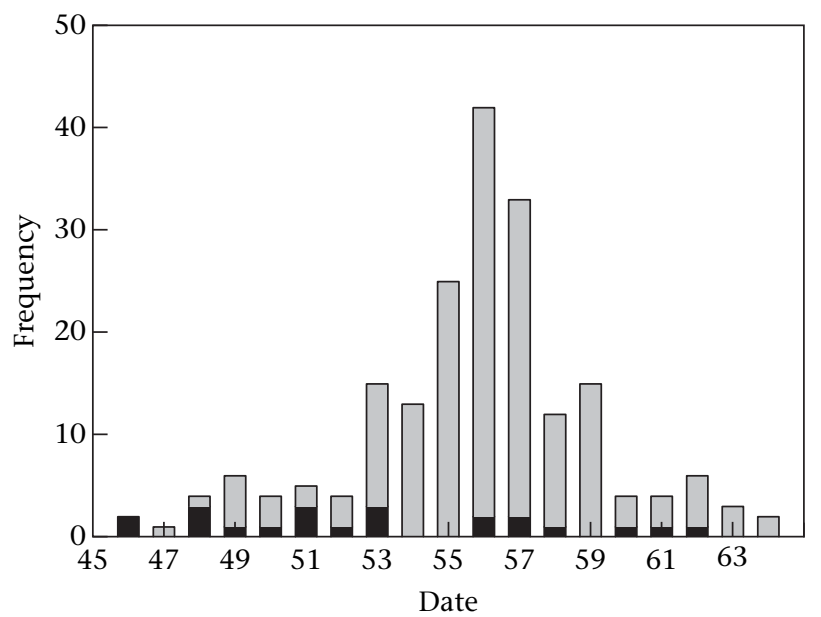

Figure 4. Seasonal variation in the number of grey-headed albatross chicks first left unattended per day from 1 December. $\mathbf{0}$ : Chicks that did not survive the first $48 \mathrm{~h}$ unattended. Note that despite the large variation in the number of chicks being left per day, the absolute number dying remains relatively constant.

raise new hypotheses concerning the mechanisms underlying the regulation of brooding.

\section{Lack of Response to Manipulations}

As chicks age and grow, we expect their ability to thermoregulate and to resist predation, but also their food requirements, to increase. These trends alone would lead us to predict that chick age should be of paramount relevance for parents making the choice between staying (to brood-guard) and leaving (to forage).

Parent grey-headed albatrosses responded weakly to the experimental manipulation of chick age, adjusting brooding by only 1.2-1.4 days when 6 days would have represented complete compensation. The magnitude of the response was similar (and in the predicted direction) for both Large and Small Chick manipulations. This result is surprising because (1) Large Chicks later suffered higher mortality, seemingly attributable to this incomplete adjustment by their foster parents and (2), without our intervention, Small Chicks (which were left at abnormally young ages), would also have experienced high mortality.

This lack of adjustment could be seen as a prudent parent response (Drent \& Daan 1980), where the maintenance of the adults' own condition (and residual reproductive value) overrides any further considerations relating to chick needs. However, we find this explanation unlikely for two main reasons. First, unmanipulated parents seemed to have a wide safety margin, allowing them to adjust brooding in relation to stage of the season and chick condition (see more detailed discussion below). Second, parents given Large Chicks were free to depart early, without incurring any costs to themselves, and probably to the advantage of their chick.

Our results suggest that adults do not use chick age per se when deciding to terminate brood guarding, even though age could be assessed by the size, morphology or 
behavioural development of the chick. Instead, parents may use alternative cues, such as an internal clock, to determine when to stop brood guarding. Endogenous timers seem to be used in similar contexts by several seabirds (Davis et al. 1995; González-Solís 2004). This could well be mediated by the hormone prolactin. In a pioneering experiment on albatrosses, Hector \& Goldsmith (1985) found that blood concentrations of prolactin declined significantly towards the end of brood guarding, leading to a relatively invariant overall duration of incubation plus brood guarding, even when the incubation period was artificially lengthened or shortened. More recent work has confirmed that prolactin secretion appears to be independent of external stimuli (Lormée et al. 1999).

Although chick age per se was apparently unimportant, grey-headed albatrosses did seem to use absolute mass (or perhaps condition) of chicks as a cue to decide when to terminate brooding (Table 2). This may help fine-tune the exact time of departure, once date and time since hatching have been taken into account, and explain why experimental birds responded to the manipulations by slightly extending or curtailing brood guarding, as appropriate.

\section{Parental Condition and Quality}

Adult body condition is generally seen as the most important single factor influencing foraging decisions of highly pelagic, long-lived, seabirds (Weimerskirch 1999). Given their large size and extreme life history strategy, albatrosses probably have a relatively wide safety margin in terms of body reserves (Weimerskirch 1995, 1999). Our results suggest that grey-headed albatrosses make decisions concerning brooding/guarding of chicks that are largely independent of their own condition. There was no correlation between parental condition and brood-guarding duration and, furthermore, the marked seasonal decline in the length of brood guarding was not paralleled by an equivalent decline in condition (late-nesting birds were not in poorer condition). These findings suggest that many birds still had a wide margin of reserves when they left their chicks for the first time, although of course this may not always be the case. Owing to small sample sizes, our analysis might not have been sensitive enough to detect a weak effect of parental condition on the duration of brood guarding.

Despite this caveat, it is none the less clear that parental condition was less important than other factors (such as date and chick condition) in the decision to cease brooding. This contrasts with results for Antarctic petrels, Thalassoica antarctica, and snow petrels, Pagodroma nivea, in which parental condition seems to have a major influence on brood-guarding duration (Tveraa et al. 1998; Tveraa \& Christensen 2002; Varpe et al. 2004; see also Brodin et al. 2003).

Brood-guarding duration could also be influenced by some parental quality effect that is not expressed in variation of adult body condition. However, we could find no evidence that low-quality individuals (individuals with low past breeding success or individuals with no previous breeding experience) brood-guarded their offspring for shorter periods than high-quality conspecifics. Furthermore, the seasonal decline in the duration of brood guarding is unlikely to be related to differences in individual quality as egg size and breeding success were not significantly related to laying date, Cobley et al. (1998) found no relation between individual quality and the timing of breeding and hatching date in our study was a powerful predictor of brood-guarding duration.

\section{To What do Parents Respond?}

Grey-headed albatross parental condition did not have a measurable influence on the regulation of brood guarding. This suggests that the decision to leave was not based on intrinsic constraints. In which case, to which alternative selection pressures do they respond? To gain further insight into this question, and propose alternative hypotheses concerning brood guarding, we first explored the patterns of chick mortality.

Despite considerable natural variability in the ages of chicks when they were left alone (range 16-39 days), this did not correlate with subsequent mortality. The growth of albatross chicks is extremely variable and chicks with an age difference of more than 10 days may well have the same body mass. Little is known about the interactions between chick age, chick mass and the ability to thermoregulate or deter predators, but it is clear that petrel chicks in good condition are better able to survive predation and other potential sources of mortality (e.g. Weidinger 1998; Tveraa \& Christensen 2002). In our study, chick condition at 21 days, but not age at the end of brood guarding, influenced chick survival probabilities. This suggests that within the range of ages observed, chick mass or condition may, to some extent, override any developmental inequalities resulting from relatively small differences in age. Note, however, that our data refer to chick mass at 21 days, several days before most chicks were left alone. Hence, the full importance of chick mass cannot be properly evaluated with the current data set.

The other important variable predicting chick survival in the first $48 \mathrm{~h}$ after the end of brood guarding was calendar date. Several studies on avian egg or chick survival have suggested that offspring of synchronized pairs suffer lower mortality rates than other more temporally isolated offspring (Wittenberger \& Hunt 1985; Hatchwell 1991; Murphy \& Schauer 1996; Weidinger 1998). Such patterns are often attributed to the benefits of collective defence against predators in colonial species and/or to the effects of predator swamping (Wittenberger \& Hunt 1985; Ims 1990). Although antipredatory behaviours are hardly ever of a collective nature in albatrosses, we believe that the latter might be operating. The only known albatross chick predators on Bird Island are brown skuas, Catharacta antarctica lonnbergi, and giant petrels, Macronectes spp. During this study, almost all predation of small chicks was carried out by skuas (unpublished data). Although Catharacta skuas are generalist predators and scavengers, individuals can display a degree of specialization. Our 
results point to a relatively constant absolute level of daily mortality in the period when chicks were being left alone (Fig. 4). One possible mechanism creating this effect is predation by (and satiation of) a number of individuals specializing on small albatross chicks and excluding other skuas through territorial behaviour (e.g. Hahn \& Peter 2003).

The negative correlation between hatching date and brood guarding could be attributed to a seasonal variation in food availability that would create a trend in broodguarding duration. A seasonal trend is also suggested by the fact that chick growth improved (albeit only slightly) for late-hatched chicks. However, all other things being equal, we would expect an increase in food availability to result in a relaxation of the conflict between foraging and guarding, with a consequent prolongation of brood guarding, if parents were trying to maximize the time spent with chicks. We found the opposite, with brood guarding being shorter when conditions allowed faster chick growth.

Given the patterns of chick mortality described above, the following adult responses could be expected to occur. (1) Parents of early hatching chicks should prolong brood guarding to avoid leaving chicks unattended during the period of high mortality risk early in the season. (2) Parents of the latest hatching chicks should curtail the duration of brood guarding so that chicks experience their critical first few days alone during the period of low overall chick mortality. (3) Parents with underweight chicks should also prolong brood guarding to allow the chick extra time for its body condition to improve. The evidence from this study suggests that the seasonal decline in brood guarding duration could be a response to predation pressure. More studies will be needed to confirm or reject this hypothesis.

\section{Acknowledgments}

We are most grateful to Ben Phalan for valuable assistance during fieldwork on Bird Island. Ben Hatchwell and two anonymous referees made helpful comments on the manuscript. Part of this study was supported by Fundação para a Ciência e a Tecnologia (FCT - Portugal) through the Programa plurianual (UI\&D 331/94) and P.C. benefited from a postdoctoral fellowship from FCT (Praxis XXI BPD/ 11631/02).

\section{References}

Brodin, A., Jönsson, I. \& Holmgren, N. 2003. Optimal energy allocation and behaviour in female raptorial birds during the nestling period. Ecoscience, 10, 140-150.

Cobley, N. D., Croxall, J. P. \& Prince, P. A. 1998. Individual quality and reproductive performance in the grey-headed albatross Diomedea chrysostoma. Ibis, 140, 315-322.

Croxall, J. P., Rothery, P. \& Crisp, A. 1992. The effect of maternal age and experience on egg-size and hatching success in wandering albatrosses Diomedea exulans. Ibis, 134, 219-228.

Davis, L. S., Cockrem, J. F., Miller, G. D. \& Court, G. S. 1995. An incubation timer for seabirds: progesterone and its relationship to hatching in Adélie penguins. Emu, 95, 245-251.
Drent, R. \& Daan, S. 1980. The prudent parent: energetic adjustment in avian breeding. Ardea, 68, 225-252.

Düttman, H., Bergmann, H.-H. \& Engländer, W. 1998. Development of behaviour. In: Avian Growth and Development (Ed. by J. M. Starck \& R. E. Ricklefs), pp. 223-246. Oxford: Oxford University Press.

González-Solís, J. 2004. The regulation of incubation shifts near hatching by giant petrels: a timed mechanism, embryonic signalling or food availability. Animal Behaviour, 67, 663-671.

Hahn, S. \& Peter, H.-U. 2003. Feeding territoriality and the reproductive consequences in brown skuas Catharacta antarctica lonnbergi. Polar Biology, 26, 552-559.

Hatchwell, B. J. 1991. An experimental study of the effects of timing of breeding on the reproductive success of common guillemots (Uria aalge). Journal of Animal Ecology, 60, 721-736.

Hector, J. A. L. \& Goldsmith, A. R. 1985. The role of prolactin during incubation: comparative studies of three Diomedea albatrosses. General and Comparative Endocrinology, 60, 236-243.

Huin, N. \& Prince, P. A. 2000. Chick growth in albatrosses: curve fitting with a twist. Journal of Avian Biology, 31, 418-425.

Hunter, S. 1984. Breeding biology and population dynamics of giant petrels Macronectes at South Georgia (Aves: Procellariiformes). Journal of Zoology, 203, 441-460.

Lormée, H., Jouventin, P., Chastel, O. \& Mauget, R. 1999. Endocrine correlates of parental care in an Antarctic winter breeding seabird, the emperor penguin, Aptenodytes forsteri. Hormones and Behavior, 35, 9-17.

Murphy, E. C. \& Schauer, J. H. 1996. Synchrony in egg-laying and reproductive success of neighboring common murres, Uria aalge. Behavioral Ecology and Sociobiology, 39, 245-258.

Ims, R. A. 1990. On the adaptive value of reproductive synchrony as a predator-swamping strategy. American Naturalist, 136, 485-498.

Phillips, R. A. \& Croxall, J. P. 2003. Control of provisioning in greyheaded albatrosses: do adults respond to chick condition? Canadian Journal of Zoology, 81, 111-116.

Prince, P. A., Rothery, P., Croxall, J. P. \& Wood, A. G. 1994. Population dynamics of black-browed and gray-headed albatrosses Diomedea melanophris and D. chrysostoma at Bird Island, South Georgia. Ibis, 136, 50-71.

Ricklefs, R. E. \& Roby, D. D. 1983. Development of homeothermy in the diving petrels Pelecanoides urinatrix exul and $P$. georgicus, and the Antarctic prion Pachyptila desolata. Comparative Biochemistry and Physiology A, 75, 307-311.

Rising, J. D. \& Somers, K. M. 1989. The measurement of overall body size in birds. Auk, 106, 666-674.

Sæther, B.-E., Andersen, R. \& Pedersen, H. C. 1993. Regulation of parental effort in a long-lived seabird: an experimental manipulation of the cost of reproduction in the Antarctic petrel, Thalassoica antarctica. Behavioral Ecology and Sociobiology, 33, 147-150.

Shaffer, S. A., Costa, D. P. \& Weimerskirch, H. 2003. Foraging effort in relation to the constraints of reproduction in free-ranging albatrosses. Functional Ecology, 17, 66-74.

Tickell, W. L. N. 2000. Albatrosses. Robertsbridge, East Sussex: Pica Press.

Tveraa, T. \& Christensen, G. N. 2002. Body condition and parental decisions in the snow petrel (Pagodroma nivea). Auk, 119, 266-270.

Tveraa, T., Sæther, B.-E., Aanes, R. \& Erikstad, K. E. 1998. Body mass and parental decisions in the Antarctic petrel Thalassoica antarctica: how long should the parents guard the chick? Behavioral Ecology and Sociobiology, 43, 73-79.

Varpe, Ø., Tveraa, T. \& Folstad, I. 2004. State-dependent parental care in Antarctic petrel: responses to manipulated chick age during early chick rearing. Oikos, 106, 479-488. 
Visser, G. H. 1998. Development of temperature regulation. In: Avian Growth and Development (Ed. by J. M. Starck \& R. E. Ricklefs), pp. 117-156. Oxford: Oxford University Press.

Warham, J. 1990. The Petrels. Their Ecology and Breeding Systems. London: Academic Press.

Weathers, W. W., Gerhart, K. L. \& Hodum, P. J. 2000. Thermoregulation in Antarctic fulmarine petrels. Journal of Comparative Physiology $B, 170,561-572$.

Weidinger, K. 1998. Effect of predation by skuas on breeding success of the Cape petrel Daption capense at Nelson Island, Antarctica. Polar Biology, 20, 170-177.

Weimerskirch, H. 1995. Regulation of foraging trips and incubation routine in male and female wandering albatrosses. Oecologia, 102, 37-43.

Weimerskirch, H. 1999. The role of body condition on breeding and foraging decisions in albatrosses and petrels. In: Proceedings of the 22nd International Ornithology Congress, Durban (Ed. by N. J.
Adams \& R. H. Slotow), pp. 1178-1189. Johannesburg: BirdLife South Africa.

Weimerskirch, H. \& Lys, P. 2000. Seasonal changes in the provisioning behaviour and mass of male and female wandering albatrosses in relation to the growth of their chick. Polar Biology, 23, 733-744.

Weimerskirch, H., Zimmermann, L. \& Prince, P. A. 2001. Influence of environmental variability on breeding effort in a long-lived seabird, the yellow-nosed albatross. Behavioral Ecology, 12, 22-30.

Wittenberger, J. F. \& Hunt, G. L., Jr. 1985. The adaptive significance of coloniality in birds. In: Avian Biology. Vol. VIII (Ed. by D. S. Farner \& J. R. King), pp. 1-78. London: Academic Press.

Wood, S. N. 2001. MGCV: GAMs and Generalized Ridge Regression for R. $R$ News, 1, 20-25.

Wood, S. N. 2003. Thin plate regression splines. Journal of the Royal Statistician Society $B, 65,95-114$. 